\title{
Argamassas fotocatalíticas e concretos com adição de fibras de coco e sisal para a redução de impactos ambientais de gases poluentes
}

\section{(Photocatalytic mortars and concretes with addition of coconut and sisal fibers to reduce environmental impacts of pollutant gases)}

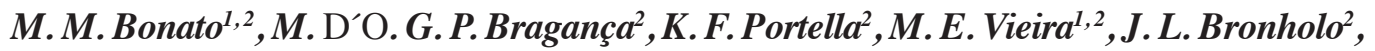 \\ J.C.M.dos Santos ${ }^{3}$, D. P.Cerqueira ${ }^{3}$ \\ ${ }^{1}$ UFPR, Universidade Federal do Paraná, Centro Politécnico da UFPR, C.P. 19011, Curitiba, PR, Brasil 81531-990 \\ ${ }^{2}$ LACTEC, Instituto de Tecnologia para o Desenvolvimento, Centro Politécnico da UFPR, BR 116, km 98, n. 8813, \\ Curitiba, PR, Brasil, 81531-990 \\ ${ }^{3}$ COELBA, Companhia de Eletricidade do Estado da Bahia, Av. Edgard Santos 300, Salvador, BA, Brasil, 41181-900
}

\begin{abstract}
Resumo
A construção civil movimenta, anualmente, toneladas de cimento para as suas mais diversas aplicações, mas, a sua fabricação gera teores elevados de poluentes ambientais. Decorrente disto tem-se uma constante busca por novos métodos sustentáveis e alternativos de fabricação. Neste trabalho, a pesquisa foi direcionada em dois aspectos: a adição de fibras de coco (FC) e de sisal (FS) a um concreto referência, com a intenção de aumentar suas demandas nacionais e diminuir o impacto ambiental resultante da quantidade de resíduos descartados no ambiente após o consumo do fruto, com redução do consumo de cimento em cada dosagem, respectivamente; e, a fotocatálise de gases poluentes por argamassas à base do nanocomposto dióxido de titânio, fase anatásio. Para a avaliação do concreto com adições foram realizados ensaios de resistência à compressão axial, variação dimensional de barras de argamassa expostas em solução agressiva de sulfato e o acompanhamento da durabilidade de corpos de prova (CPs) envelhecidos em câmaras de intemperismo de névoa salina e de dióxido de enxofre pela técnica do potencial de corrosão. As argamassas com $\mathrm{TiO}_{2}$ foram avaliadas quanto ao seu potencial fotocatalítico para a redução na concentração de gases tipo $\mathrm{NO}_{x}$ em câmara de UV-A, produzida para esta verificação. Os resultados indicaram um aumento em até $16 \%$ da resistência mecânica dos concretos com adições e uma eficiência das argamassas com teores de nano $\mathrm{TiO}_{2}$-fase anatásio a partir de $20 \%$ em massa, para promover a fotocatálise do $\mathrm{NO}_{\mathrm{x}}$ ao redor de $40 \%$, em presença de radiação UV-A.

Palavras-chave: concreto com adições, fibras de coco, fibras de sisal, durabilidade, argamassa fotocatalítica.
\end{abstract}

Abstract

The construction moves annually, tons of cement for their diverse applications, but their manufacturing generates high levels of environmental pollutants. Resulting from this is a constant search for new sustainable and alternative methods. In this work, the research was directed at two aspects: the addition of coconut fibers $(C F)$ and sisal (SF) to a concrete reference, with the intention of increasing their national demands and diminishes the impact of the amount of waste disposed the environment after consumption of the fruit and reducing the cement consumption in each dosage, respectively; and photocatalysis of gaseous pollutants by mortars based nanocomposite titanium dioxide, anatase phase. For the evaluation of concrete with additions testing compressive strength, dimensional change of mortar bars exposed to aggressive sulfate solution and monitoring the durability of specimens aged in chambers salt spray and weathering dioxide were performed the technique of sulfur corrosion potential. Mortars with TiO ${ }_{2}$ were evaluated for their potential for photocatalytic reduction in the concentration of $N O_{x}$ in gas type UV-A chamber. The results showed an increase up to $16 \%$ of the strength of concrete with additions and efficiency of mortars with levels of nano TiO ${ }_{2}$ anatase-phase from $20 \%$, by weight, to promote photocatalysis of $N O_{x}$ around $40 \%$ in the presence $U V$-A radiation.

Keywords: concrete additions, coconut fiber, sisal fiber, durability, photocatalytic mortar.

\section{INTRODUÇÃO}

A construção civil movimenta toneladas anuais de cimento para as suas mais diversas aplicações, mas, a fabricação deste aglomerante é um grande poluidor do meio ambiente. Estima-se uma média mundial de emissão de 800 $\mathrm{kg}$ de $\mathrm{CO}_{2}$ para cada tonelada de cimento produzido [1]. Outro problema ambiental comum é a grande quantidade de rejeitos que poderiam ser utilizados e são depositados em aterros sanitários e afins. Em âmbito nacional temse o coco verde, cuja água é amplamente consumida em cidades litorâneas. O coco, que em 2007 teve no Brasil uma produção aproximada de 1,9 milhões de toneladas, tem como resíduo cerca de $80 \%$ de seu fruto [2]. Assim, pode-se estimar para a ocasião uma geração de resíduos, aproximadamente 1,5 milhões de toneladas, ou um volume 
de aterro sanitário, subutilizado, da ordem de $10.000 \mathrm{~m}^{3}$, por um período médio para a sua decomposição de 12 anos [2, 3]. As fibras, obtidas do mesocarpo de cocos, são materiais lignocelulósicos caracterizados por sua dureza e durabilidade, atribuída ao alto teor de lignina, quando comparadas com outras fibras naturais [4]. As suas principais características são: baixa densidade, grande percentual de alongamento e baixos valores para a resistência à tração e módulo de elasticidade. A sua utilização em um compósito tende a diminuir a densidade do material com um bom potencial de alongamento e média capacidade de reforço, porém com possibilidades de melhorar o desempenho da interação fibramatriz devido à ação aglutinante da lignina. As fibras de coco já foram estudadas como substitutas do asbesto, já que se confirmou ser este responsável por sérios problemas à saúde, pontualmente a doença asbestose [5]. Placas corrugadas de fibrocimento usando fibras de coco foram produzidas e caracterizadas, sendo concluído que a sua eficiência foi semelhante à obtida com asbesto [6]. Estudos voltados para materiais de construção leves, contendo cimento, areia e fibras de resíduos de coco jovens foram desenvolvidos, sendo observada a redução da condutividade térmica e a diminuição da densidade do compósito, sem comprometer as características necessárias à sua utilização; recomendando seu uso em paredes e telhados [7].

Outro produto de interesse para aumentar a demanda nacional é a fibra de sisal, uma vez que o Brasil é o seu maior produtor mundial, com 140 mil toneladas anuais [8]. Atualmente, o estado da Bahia é responsável por $80 \%$ desta produção. O sisal é uma fibra lignocelulósica leve e atóxica, originada no México e denominada assim devido a uma erva nativa chamada Zizal-Xiu, ao nome de um povoado e ao porto por onde a fibra era exportada [9]. Estas são obtidas na forma de feixes, variando de 0,40 a $2 \mathrm{~m}$ de comprimento, com secção angular ou quase cilíndrica, mais espessas na base e de coloração branco-creme [10]. A sua extração é feita por corte e desfibramento, seguindo a lavagem, secagem e limpeza. Cada fibra de sisal é constituída por um ou mais feixes fibrosos, os quais contêm um grande número de células justapostas e intimamente ligadas por uma substância de natureza péctica, que não se separa nas operações de manufatura. Desta forma, classificam-se como duras ou vasculares, por serem espessas, ásperas e rígidas, diferenciando-se do outro grupo das fibras macias ou liberianas de constituição mais fina, macia e flexível [10]. São consideradas estruturais e apresentam as seguintes características [11-13]: i) são biodegradáveis, sendo produzidas de fonte renovável; ii) possuem a facilidade de se modificar superficialmente devido a sua textura, permitindo uma boa aderência de contato; iii) têm alta tenacidade; iv) possuem boas propriedades de isolamentos térmicos e acústicos, com elevada resistência ao calor; v) possuem menor custo quando comparado à fibra de vidro; e, vi) têm excelente resistência à abrasão, especialmente em equipamentos e moldes. No entanto, apresentam como desvantagem, para a aplicação desta pesquisa, um alto teor de açúcares na sua composição, podendo retardar o tempo de pega do concreto.
Buscando-se, ainda, tecnologias que possam favorecer a redução de impactos ambientais, tem-se a fotocatálise heterogênea, a qual pode ser aplicada para a redução de gases poluentes, por meio do emprego de nanocomposto à base de $\mathrm{TiO}_{2}$, fase anatásio ou outros agentes oxidantes químicos, como o $\mathrm{ZnO}$. A eficácia destes materiais e seus mecanismos de atuação podem ser verificados na literatura [14-18], onde foram citados estudos elaborados por diversos autores, os quais provaram ser possível decompor $\mathrm{NO}_{x}$, $\mathrm{SO}_{x}, \mathrm{NH}_{3}$ e compostos orgânicos nocivos à saúde como o benzeno, o tolueno e a acetona e transformá-los em substâncias mais inócuas. Aplicações em escala laboratorial mostraram a possibilidade de se reduzir em até $63 \%$ o teor de tolueno [19]; e de até $80 \%$ o teor de $\mathrm{NO}_{x}$ [20]. $\mathrm{Na}$ construção civil, o uso desta técnica teve início na década de 1990, no Japão, quando as empresas e as universidades iniciaram os testes em concretos e em placas cerâmicas. Desde então, o interesse pela sua aplicação a outros materiais tem crescido em todo o mundo, principalmente, por conta do seu potencial de tornar as superfícies autolimpantes e por possibilitar a transformação de partículas poluentes como $\mathrm{NO}_{x}$ e os compostos orgânicos voláteis, COVs (tolueno, xileno, em compostos menos agressivos como $\mathrm{CO}_{2}, \mathrm{H}_{2} \mathrm{O}$, $\mathrm{O}_{2}$ ). Em termos de tecnologias, têm-se aplicações em escala piloto em pavimentos cimentícios em vários países como Japão, Itália, França, Bélgica e Holanda [21]. Também, foram testadas em pavimentos de concreto e em pisos intertravados ("pavers"). Os resultados confirmaram os dados obtidos em escala laboratorial com reduções de até $40 \%$ na concentração de $\mathrm{NO}_{x}$ nas vias onde foram utilizados produtos com propriedades fotocatalíticas.

Neste trabalho foram produzidas e estudadas diversas composições de argamassa fotocatalítica, variando-se o teor do nanocomposto $\mathrm{TiO}_{2}(0,5,10,20,50,70$ e $90 \%)$, fase anatásio e, também, estruturas de concreto com adições de fibras naturais de coco e sisal $(0,6 ; 0,8$ e 1,0\%). Ambos os materiais objetivaram a redução de gases poluentes na atmosfera, e a redução do consumo médio de cimento por $\mathrm{m}^{3}$ de produto fabricado, pela aplicação no setor elétrico, uma vez que este possui, em média, $400 \mathrm{~m}^{2} / \mathrm{km}$ de área superficial aérea de concreto em redes aéreas de distribuição e de transmissão de energia áreas superficiais de concreto.

\section{MATERIAIS E MÉTODOS}

$\mathrm{Na}$ produção do concreto foram utilizados: cimento Portland pozolânico tipo CP II-Z 32; agregado miúdo (areia natural lavada); agregado graúdo, constituído de rocha britada, tipo basáltica, com dimensão máxima de $9,5 \mathrm{~mm}$; fibras naturais de coco e de sisal, ambas disponíveis no mercado nacional; dióxido de titânio AEROXIDE® $\mathrm{TiO}_{2}$ $\mathrm{P}_{25}$, fase anatásio, com distribuição média de partículas da ordem de $25 \mathrm{~nm}$; e água potável para o amassamento da argamassa e do concreto.

As fibras foram cortadas em moinho de facas NZ Philpolymer JHL-240, com comprimento aleatório entre 15 e $35 \mathrm{~mm}$, Fig. 1. Por motivos experimentais, um novo estudo 
foi realizado considerando-se os comprimentos das fibras de coco e sisal menores e em torno de $10 \mathrm{~mm}$. Além disso, as características das fibras foram investigadas com e sem tratamento alcalino. Este tratamento consistiu na imersão e agitação mecânica das fibras moídas em solução de $1 \%$ de $\mathrm{NaOH} / 1$ h. Após, as fibras foram lavadas com água, a fim de remover todas as impurezas e as substâncias solúveis provenientes do tratamento químico. As fibras foram secas em estufa a $60{ }^{\circ} \mathrm{C}$ por $24 \mathrm{~h}$.
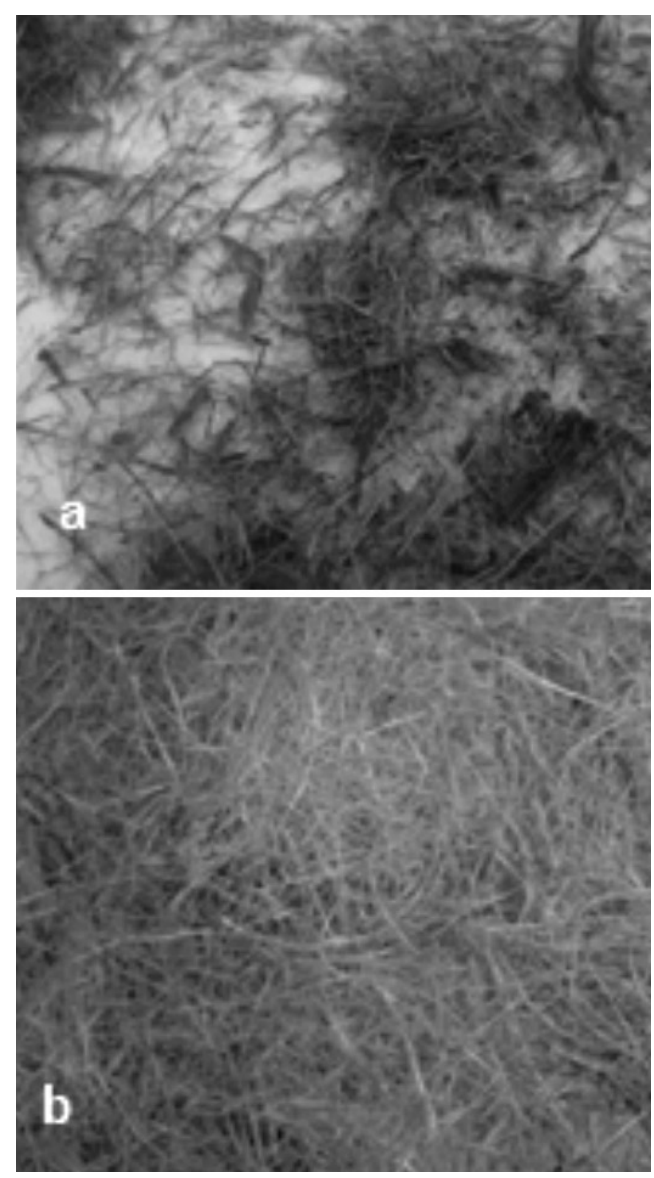

Figura 1: Fibras naturais: coco (a) e sisal (b). [Figure 1: Natural fibers: coconut (a) and sisal (b).]

Cimento foi caracterizado por análises físico-químicas, realizadas em acordo com as normas brasileiras [2231]. O objetivo foi identificar os compostos químicos presentes, incluindo aqueles que influenciam na vida útil das estruturas de concreto em função do tempo (tais como: $\mathrm{Na}_{2} \mathrm{O}$ e $\mathrm{K}_{2} \mathrm{O}, \mathrm{CaO}$ livre, $\mathrm{MgO}$ e $\mathrm{SO}_{3}$ ), além de verificar se $\mathrm{o}$ produto se encontrava dentro do especificado pelo fabricante. Agregados: os agregados miúdo e graúdo foram caracterizados de acordo com a NBR7211/09 [32]. Fibras de coco e sisal, FC e FS: para obtenção da massa específica das fibras foi utilizado o método do picnômetro (ASTM D2320) [33]. Dióxido de titânio: a caracterização da substância fotocatalítica foi realizada a partir da técnica de difração de raios X (DRX), para identificar a fase cristalina predominante. Para tanto, foi utilizado um equipamento
Philips X'Pert MPD, nas condições de $40 \mathrm{kV}$ e $40 \mathrm{~mA}$, radiação Cuk $\alpha$, varredura angular $2 \theta$ entre 5 e $90^{\circ}$, com velocidade de passo $0,01 \%$ s. A identificação das fases foi feita por meio dos arquivos ICDD. Foi definido um traço referência para o estudo como sendo 1:1,48:2,52:0,50, sendo estes os valores para cimento, areia, brita e relação água/ cimento em sequência. A partir da referência, concretos com adições de FS e FC foram desenvolvidos contendo 0,6\%, $0,8 \%$ e $1,0 \%$, em massa, de fibra em relação ao consumo de cimento. A moldagem dos CPs para os ensaios foi realizada em acordo com a norma NBR 5738/03 [34].

Caracterização do concreto por resistência à compressão axial: o estudo de resistência à compressão axial simples foi realizado de acordo com a norma NBR 5739/2009 [35]. Os concretos produzidos foram utilizados para confecção de CPs cilíndricos $(10 \times 20) \mathrm{cm}$, que foram previamente cobertos por um filme plástico e curados ao ar livre por $24 \mathrm{~h}$ e, então, desformados e armazenados em câmara para cura úmida até a data de ensaio. Foram produzidos $10 \mathrm{CPs}$, por dosagem, dois para cada idade de 3, 7, 14, 28 e 91 dias.

Envelhecimento acelerado em câmara de intemperismo: foram confeccionados CPs para acompanhamento da durabilidade em câmara de intemperismo, moldados nas mesmas condições do concreto utilizado para resistência a compressão axial, em formato prismático com dimensões de (91 x 49) $\mathrm{mm}$ de base e $100 \mathrm{~mm}$ de altura, sendo dotada de barras metálicas confeccionadas a partir de vergalhões nervurados de aço carbono CA 50 de $6,3 \mathrm{~mm}$ de diâmetro nominal e $125 \mathrm{~mm}$ de comprimento, Fig. 2. Estas barras metálicas foram polidas em esmeril e encapadas com fita de autofusão para padronização, ou seja, eliminou-se a camada de óxido passivante já existente e delimitou-se a área central de $35 \mathrm{~mm}$ de altura da barra como região a ser corroída. Estas amostras foram armazenadas em câmaras de intemperismo, em atmosfera agressiva de sulfato (ASTM G 87-02) [36] e cloreto (ASTM B 117-09) [37], simulando condições de meio industrial e marinho, sendo submetidas a ciclos de molhagem e secagem, a temperaturas de até $40^{\circ} \mathrm{C}$. A durabilidade dos materiais foi acompanhada em função das alterações nas propriedades elétricas dos mesmos, por meio de potencial de corrosão da armadura medido com potenciostato/galvanostato Autolab, de alta impedância de entrada em célula eletroquímica contra um eletrodo de cobre|sulfato de cobre (CSE). Os valores obtidos foram avaliados de forma qualitativa segundo a norma ASTM C-876 [38], indicando a probabilidade de haver um processo de corrosão do sistema concreto armado. As amostras investigadas foram: concreto-referência (sem adições); concreto com adição de $0,8 \%$ de FS; concreto com adição de $0,8 \%$ de FC.

Caracterização da variação dimensional de barras de argamassa: para a avaliação da durabilidade, foi realizado o ensaio de variação dimensional de barras de argamassa expostas em solução agressiva de sulfato, seguindo a NBR 13583/96 [39]. Foram preparadas barras na forma de paralelepípedos com $250 \mathrm{~mm}$ de comprimento e $25 \mathrm{~mm}$ de altura e largura, de argamassa referência e com adições de 


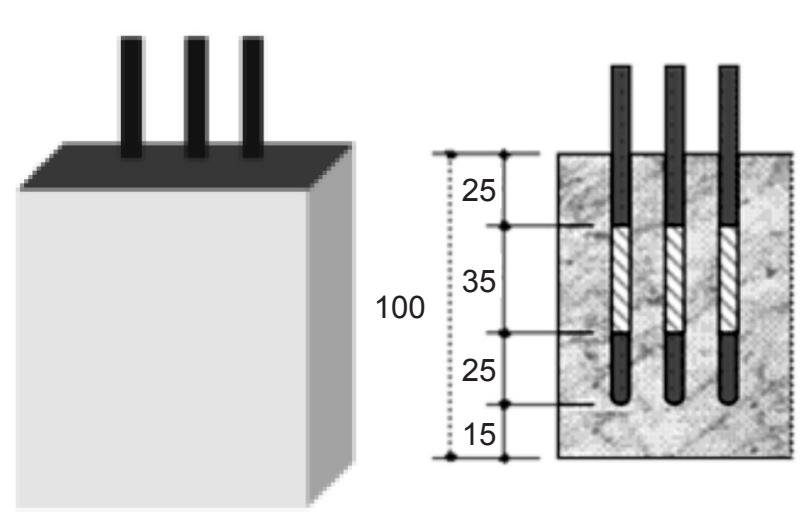

Figura 2: Desenho esquemático do $\mathrm{CP}$ prismático para o ensaio de durabilidade e detalhe interno das barras com as dimensões de exposição em mm [16].

[Figure 2: Schematic representation of the prismatic specimen for the durability test and the inside details of the reinforcing steel with its exposure dimensions in $\mathrm{mm}$.]

$0,6 \%$ FS e $0,8 \%$ FC, para envelhecimento acelerado em solução de sulfato. O traço utilizado foi o mesmo do concretoreferência, mas com brita moída. As barras passaram por um processo de cura inicial em câmara úmida por $48 \mathrm{~h}$, seguida de uma cura intermediária em solução saturada de cal por 12 dias e, então, a cura final em solução aquosa agressiva de sulfato de sódio, com $100 \mathrm{~g}$ de $\mathrm{Na}_{2} \mathrm{SO}_{4} / \mathrm{L}$, por 42 dias. As medidas de variação dimensional foram realizadas ao fim da cura intermediária e aos 14, 28 e 42 dias de cura final.

Caracterização micrográfica, por microscopia eletrônica de varredura (MEV), na superfície de fratura dos CPs: os corpos de prova submetidos ao envelhecimento acelerado em soluções de $\mathrm{Na}_{2} \mathrm{SO}_{4}$ e em câmara de $\mathrm{SO}_{2}$ foram analisados, após a finalização dos testes mecânicos e físicos dimensionais, em um equipamento Philips XL 30, com metalização superficial com ouro por deposição catódica em alto vácuo.

Potencial fotocatalítico da argamassa contendo $\mathrm{TiO}_{2}$, fase anatásio em diferentes concentrações: para o estudo de fotocatálise, foram moldadas amostras de argamassa com espessura de $18 \mathrm{~mm}$ e com cobertura fotocatalítica de $2 \mathrm{~mm}$. O traço utilizado no substrato foi semelhante ao concretoreferência e estabelecido em 1:3:0,4 (cimento: areia retida na peneira $2,4 \mathrm{~mm}$ : fator a/c). Para a superfície, foram estudadas diversas concentrações de $\mathrm{TiO}_{2}$ (em substituição ao cimento), variando de 0 a $90 \%$. O traço adotado foi de 1:3 (cimento: areia passante na peneira $2,4 \mathrm{~mm}$ ), e o a/c (relação água/cimento) variou de 0,4 a 2,0, devido à variação da quantidade de nanomaterial adicionado. As amostras permaneceram em cura ambiente com cobertura de filme plástico por, aproximadamente, $48 \mathrm{~h}$ e, em cura úmida, por cerca de uma semana, antes da realização dos ensaios de determinação do potencial fotocatalítico. Para a medida da eficiência de conversão de gás $\mathrm{NO}_{x}$ pela fotocatálise, foram realizadas análises de absorção/reação com geradores de concentrações conhecidas deste gás. No ensaio teve-se como sequência: 1) um teor de gás $\mathrm{NO}_{x}$ padrão (em torno de $1,2 \mathrm{ppm}$ e fluxo de $0,7 \mathrm{~L} / \mathrm{min}$ ), que foi injetado em um reator e seu volume foi medido e estabilizado em um conjunto de equipamentos calibradores digitais, Multigás, MGC 101 e ZAG 7001, respectivamente; 2) a concentração do gás foi medida anterior e posteriormente ao processo de reação de fotocatálise por intermédio de um monitor de gás marca Horiba, modelo "Ambient Monitor; 3) a célula do reator foi fabricada em tubo PVC de $100 \mathrm{~mm}$ de diâmetro contendo tampas laterais com sistemas de entrada do gás (proveniente dos calibradores de volume) e saída, esta, direcionada para o monitor de gás Horiba. No interior desta célula, foi instalada uma lâmpada fria UV-A (emitindo radiação com comprimento de onda entre 320 e $400 \mathrm{~nm}$ ), acionada externamente por uma chave liga/desliga. 4) o desempenho das misturas foi avaliado ao longo do tempo de exposição ao gás com a radiação UV-A emitida.

\section{RESULTADOS E DISCUSSÃO}

Cimento: a caracterização física, química e mecânica do cimento CP II-Z 32 foi verificada segundo as normas da ABNT [22-31]. Esses resultados estão apresentados nas Tabelas I a III e atestaram a conformidade do material para a fabricação dos traços de concreto.

Agregados: a distribuição granulométrica do agregado miúdo ficou na zona ótima, conforme especificação de agregados para concreto da NBR 7211/2009 [32]. As propriedades do agregado miúdo obtidas nos ensaios físicos estão listadas na Tabela IV, e estão dentro dos limites

Tabela I - Ensaios físicos e mecânicos do cimento CP I-Z 32.

[Table I - Physical and mechanical tests of CP II-Z 32 cement.]

\begin{tabular}{lll}
\hline Ensaios Físicos & & \\
\hline Resíduo peneira & $\# 200$ & $2,60 \%$ \\
& $\# 325$ & $8,80 \%$ \\
Finura Blaine & $3,790 \mathrm{~cm}^{2} / \mathrm{g}$ & \\
Expansão à quente & $0,0 \mathrm{~mm}$ & \\
Massa específica & $3,040 \mathrm{~g} / \mathrm{cm}^{3}$ & \\
Tempo de pega & início & $4 \mathrm{~h} 20 \mathrm{~min}$ \\
& fim & $5 \mathrm{~h} 50 \mathrm{~min}$ \\
Resistência à & 3 dias & $23,0 \mathrm{MPa}$ \\
compressão & 7 dias & $26,4 \mathrm{MPa}$ \\
& 28 dias & $32,8 \mathrm{MPa}$ \\
\hline
\end{tabular}

Tabela II - Ensaios químicos do cimento CP II-Z 32. [Table II - Chemical tests of CP II-Z 32 cement.]

\begin{tabular}{ll}
\hline Ensaios Químicos & \\
\hline Perda ao fogo & $0,21 \%$ \\
Resíduo insolúvel & $7,07 \%$ \\
Teor de CaO livre & $6,96 \%$ \\
\hline
\end{tabular}


Tabela III - Composição química do cimento CP II-Z 32.

[Table III - Chemical composition of CP II-Z 32 cement.]

\begin{tabular}{lccccccccccc}
\hline Componentes & $\mathrm{CaO}$ & $\mathrm{SiO}_{2}$ & $\mathrm{Al}_{2} \mathrm{O}_{3}$ & $\mathrm{MgO}$ & $\mathrm{Fe}_{2} \mathrm{O}_{3}$ & $\mathrm{SO}_{3}$ & $\mathrm{MnO}$ & $\mathrm{TiO}_{2}$ & $\mathrm{~K}_{2} \mathrm{O}$ & $\mathrm{P}_{2} \mathrm{O}_{5}$ & $\mathrm{Na}_{2} \mathrm{O}$ \\
\hline Teor em massa (\%) & 54,8 & 21,53 & 4,73 & 5,43 & 2,94 & 2,66 & 0,03 & 0,24 & 0,97 & 0,10 & 0,19 \\
\hline
\end{tabular}

Tabela IV - Características do agregado miúdo. [Table IV - Characteristics of the fine aggregate.]

\begin{tabular}{ll}
\hline Propriedade & Valores \\
\hline Módulo de finura & 2,46 \\
Dimensão máxima característica & $4,75 \mathrm{~mm}$ \\
Massa específica & $2,52 \mathrm{~g} / \mathrm{cm}^{3}$ \\
Massa unitária & $1,57 \mathrm{~g} / \mathrm{cm}^{3}$ \\
Absorção & $0,40 \%$ \\
Teor de material pulverulento & $5,60 \%$ \\
Teor de argila em torrões & $0,30 \%$ \\
Teor de impurezas orgânicas & $>300 \mathrm{ppm}$ \\
\hline
\end{tabular}

Tabela V - Características do agregado graúdo. [Table V-Characteristics of the coarse aggregate.]

\begin{tabular}{ll}
\hline Propriedade & Valores \\
\hline Módulo de finura & 5,61 \\
Dimensão máxima característica & $9,50 \mathrm{~mm}$ \\
Massa específica seca & $2,55 \mathrm{~g} / \mathrm{cm}^{3}$ \\
Massa específica SSS & $2,58 \mathrm{~g} / \mathrm{cm}^{3}$ \\
Massa unitária & $1,39 \mathrm{~g} / \mathrm{cm}^{3}$ \\
Absorção & $1,10 \%$ \\
\hline
\end{tabular}

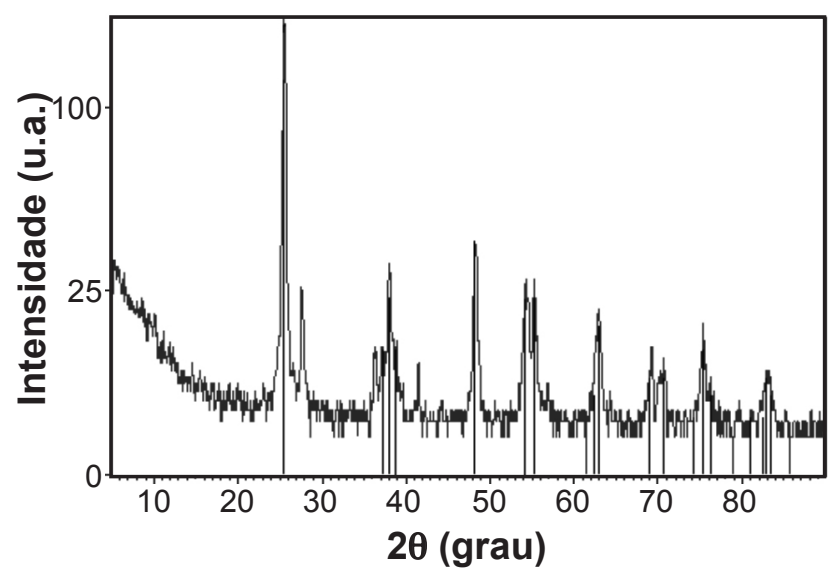

Figura 3: Difratogramas de raios $\mathrm{X}$ da amostra de $\mathrm{TiO}_{2}$, com identificação da fase predominante anatase.

[Figure 3: XRD pattern of the $\mathrm{TiO}_{2}$ sample with identification of the anatase predominant phase.]

estabelecidos pelas normas brasileiras. As características do agregado graúdo encontram-se na Tabela $\mathrm{V}$.

Fibras de coco e sisal: os valores obtidos de massa específica foram de 1,370 e $1,270 \mathrm{~g} / \mathrm{cm}^{3}$, respectivamente, para FC e FS. Dióxido de titânio: a análise feita pela técnica de DRX indicou que a fase predominante na amostra de pó ensaiada foi a anatásio, conforme difratograma apresentado na Fig. 3, com as linhas indicativas do material padrão dado pelo banco de dados do ICDD. Esta é a fase de maior atividade fotocatalítica do material [40].

Concretos e argamassas: resistência à compressão axial simples: os resultados de compressão axial estão apresentados na Tabela VI e Figs. 4 e 5. Os concretos com adições de $\mathrm{FC}$ e FS apresentaram valores de resistência à compressão axial até $16 \%(0,8 \%$ FC) superiores ao mínimo exigido pelas normas brasileiras que é de $31,6 \mathrm{MPa}$ aos 28 dias, considerando a curva de distribuição normal, com exceção da $1,0 \%$ FS. Isto se deve à qualidade na produção dos concretos, especialmente na colocação dos componentes e homogeneização das fibras, propiciando uma estrutura homogênea, com boa distribuição e coesão das mesmas no concreto endurecido. Os dados obtidos de resistência à compressão aos 28 dias para as dosagens com tratamento alcalino foram inferiores em até 4,6\% para as FC e de $11,3 \%$ para as de sisal. Tal fato indicou que o tratamento alcalino das fibras não trouxe vantagens para a resistência mecânica, tornando-se desnecessário a sua execução, também por gastos de produção.

Variação dimensional das argamassas: com os resultados do teste de variação dimensional foi possível notar que a argamassa com adição de $0,6 \%$ FS teve uma maior expansão (44\% em relação à referência e 51\% à $0,8 \%$ FC) do que a dosagem com $0,8 \%$ FC a qual se comportou de forma semelhante à argamassa sem adições, conforme resultados mostrados na Tabela VII e Fig. 6. A análise micrográfica por MEV de ambos os materiais envelhecidos em câmara de $\mathrm{SO}_{2}$, corroboraram com a maior facilidade de formação de cristais na primeira composição (Fig. 7). A composição com fibra de coco mostrou ser mais efetiva à ação deste contaminante ambiental. Tal fato pode estar relacionado à propriedade da FS de absorver e reter maior teor de água, cerca de $10 \%$ superior à da $\mathrm{FC}$, observado em análise termogravimétrica [41] e, por isso, facilitar a cristalização de sais no interior da argamassa.

Fotocatálise: no ensaio foi possível verificar o desempenho das argamassas estudadas (com e sem $\mathrm{TiO}_{2}$ ) quanto a sua influência na fotocatálise do gás $\mathrm{NO}_{x}$, sob radiação UV-A. Na Fig. 8, está representada uma das amostras com cobertura fotocatalítica com dosagem equivalente a $90 \%$, em massa, de $\mathrm{TiO}_{2}$ quando exposta à radiação UV-A. De todas as composições testadas, a argamassa com $20 \%$ de $\mathrm{TiO}_{2}$ (\% em massa) foi selecionada por demonstrar melhor eficiência fotocatalítica e, portanto, ecológica, com, aproximadamente, $40 \%$ de degradação do 
Tabela VI - Resistência à compressão axial de corpos de prova sem (CP referência) e com adições de FC e FS. [Table VI - Compression resistance of specimens with and without fibers addition.]

\begin{tabular}{|c|c|c|c|c|c|c|c|}
\hline \multirow{2}{*}{ Tempo } & \multicolumn{7}{|c|}{ Resistência à compressão (MPa) } \\
\hline & CP referência & $0,6 \% \mathrm{FC}$ & $0,8 \% \mathrm{FC}$ & $1,0 \% \mathrm{FC}$ & $0,6 \% \mathrm{FS}$ & $0,8 \% \mathrm{FS}$ & $1,0 \% \mathrm{FS}$ \\
\hline 3 dias & $17,3 \pm 0,8$ & $20,3 \pm 0,1$ & $22,2 \pm 0,3$ & $19,8 \pm 0,6$ & $18,9 \pm 0,5$ & $13,6 \pm 0,1$ & $10,3 \pm 0,7$ \\
\hline 7 dias & $28,2 \pm 1,3$ & $26,0 \pm 1,4$ & $28,4 \pm 1,0$ & $24,4 \pm 1,2$ & $26,3 \pm 0,6$ & $25,5 \pm 2,4$ & $21,0 \pm 1,5$ \\
\hline 14 dias & $32,4 \pm 2,9$ & $30,6 \pm 1,8$ & $31,2 \pm 1,4$ & $28,8 \pm 1,5$ & $32,0 \pm 0,2$ & $24,9 \pm 2,4$ & $25,7 \pm 0,3$ \\
\hline 28 dias & $35,1 \pm 1,6$ & $33,9 \pm 0,3$ & $36,8 \pm 2,9$ & $32,0 \pm 0,7$ & $35,8 \pm 0,1$ & $34,1 \pm 2,4$ & $29,1 \pm 0,1$ \\
\hline
\end{tabular}

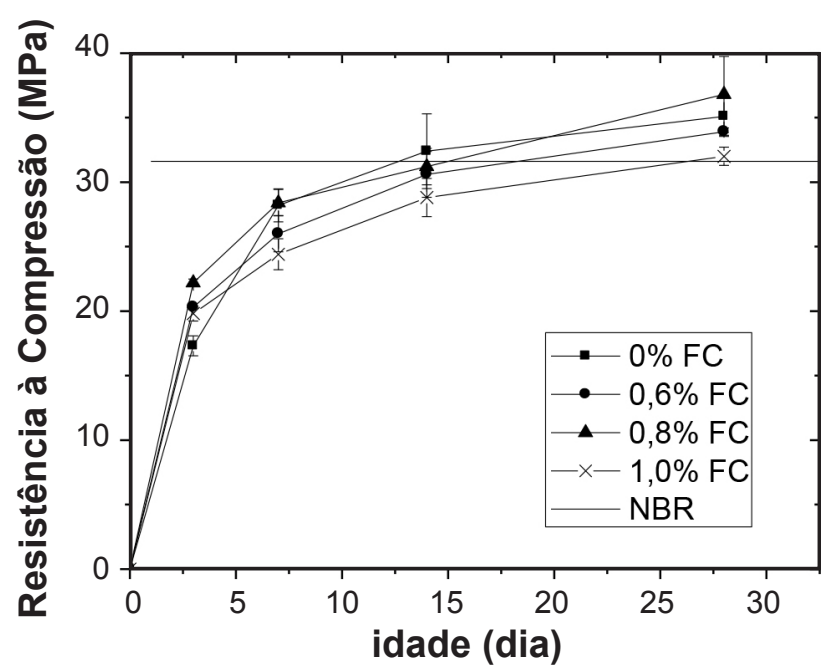

Figura 4: Resistência à compressão axial dos concretos com adição de fibras de coco.

[Figure 4: Compression resistance of the concrete with coconut fibers addition.]

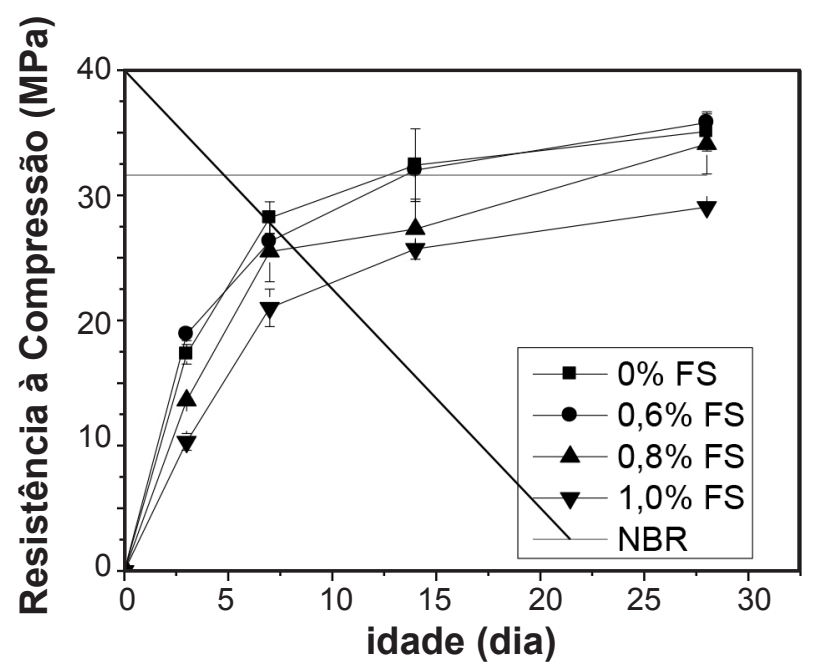

Figura 5: Resistência à compressão axial dos concretos com adição de fibras de sisal.

[Figure 5: Compression resistance of the concrete with sisal fibers addition.]
Tabela VII - Variação dimensional de barras de argamassa em solução agressiva de sulfato.

[Table VIII - Dimensional variation of mortar bars in sulfate aggressive solution.]

\begin{tabular}{ccccc}
\hline & \multicolumn{4}{c}{ Expansão (\%) } \\
Amostra / Dias & 0 & 14 & 28 & 42 \\
\hline Referência & 0 & 0,061 & 0,084 & 0,109 \\
$0,6 \%$ FS & 0 & 0,078 & 0,116 & 0,157 \\
$0,8 \%$ FC & 0 & 0,080 & 0,093 & 0,104 \\
\hline
\end{tabular}

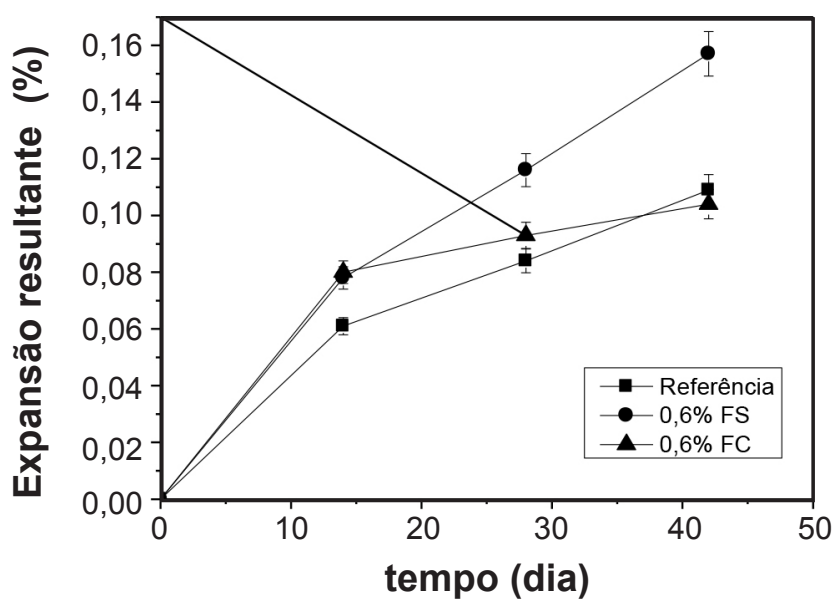

Figura 6: Variação dimensional de barras de argamassa em solução agressiva de sulfato.

[Figure 6: Dimensional variation of mortar bars in sulfate aggressive solution.]

$\mathrm{NO}_{\mathrm{x}}$ conforme pode ser observado na Fig. 9. Também, dada a pequena quantidade percentual da adição, a sua relação custo versus benefício foi menor.

Envelhecimento acelerado em câmara de intemperismo: as curvas de potencial de corrosão dos concretos submetidos ao envelhecimento natural e acelerado, ao longo do tempo, seguindo as recomendações da ASTM C 876 [38] por, aproximadamente, 300 dias, estão apresentadas nas Figs. 10 a 12. 

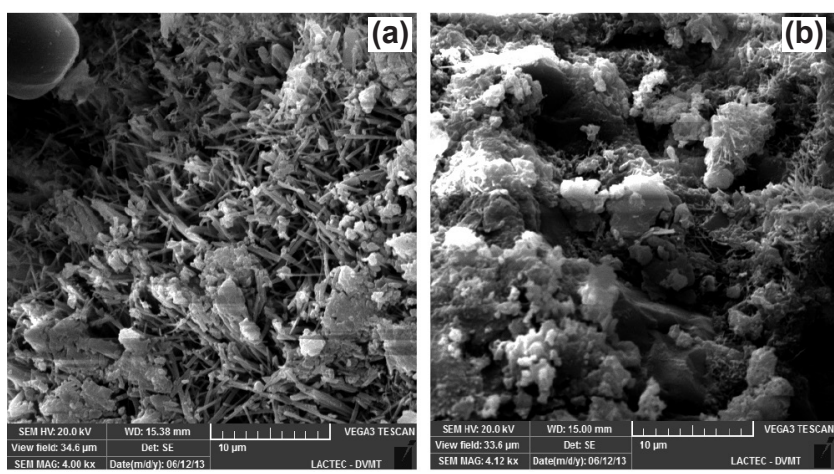

Figura 7: Micrografias por microscopia eletrônica de varredura dos corpos de prova de concreto envelhecidos em câmara de $\mathrm{SO}_{2}$ com ampliações de 4000x: (a) CP 8 B-FS; e (b) CP 6 B-FC.

[Figure 7: SEM micrographs of concrete samples aged in $\mathrm{SO}_{2}$ chamber with magnifications of 4000x: (a) $C P$ 8B-FS; and (b) $C P$ $6 B-F C$.]

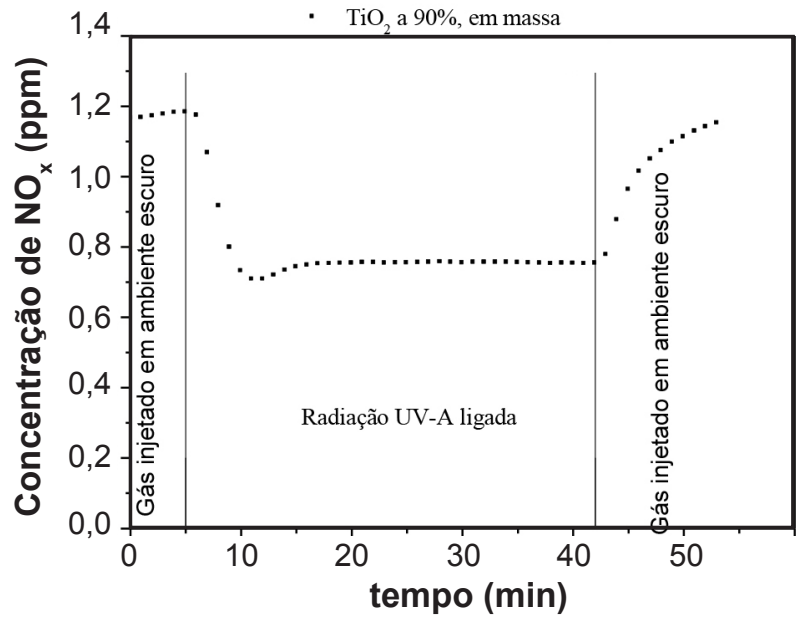

Figura 8: Teste de degradação fotocatalítica do poluente $\mathrm{NO}_{x}$ com ação ultravioleta de uma lâmpada UV-A em amostras com $90 \%$ $\mathrm{TiO}_{2}$.

[Figure 8: Photocatalytic degradation test of the pollutant $\mathrm{NO}_{x}$ with ultraviolet action of a UV-A lamp in specimens with $90 \%$ $\mathrm{TiO}_{2}$.]

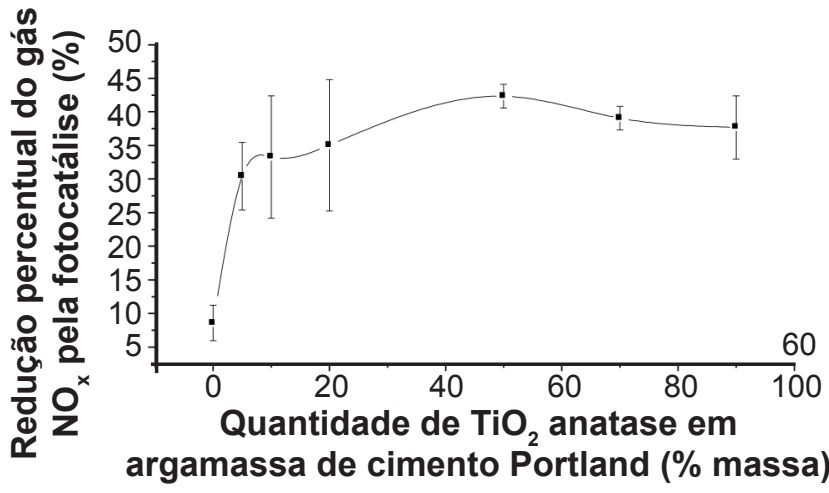

Figura 9: Testes de degradação fotocatalítica do poluente $\mathrm{NO}_{x}$ com ação ultravioleta de uma lâmpada UV-A.

[Figure 9: Photocatalytic degradation test of the pollutant $N \mathrm{O}_{x}$ with ultraviolet action of a UV-A lamp.]

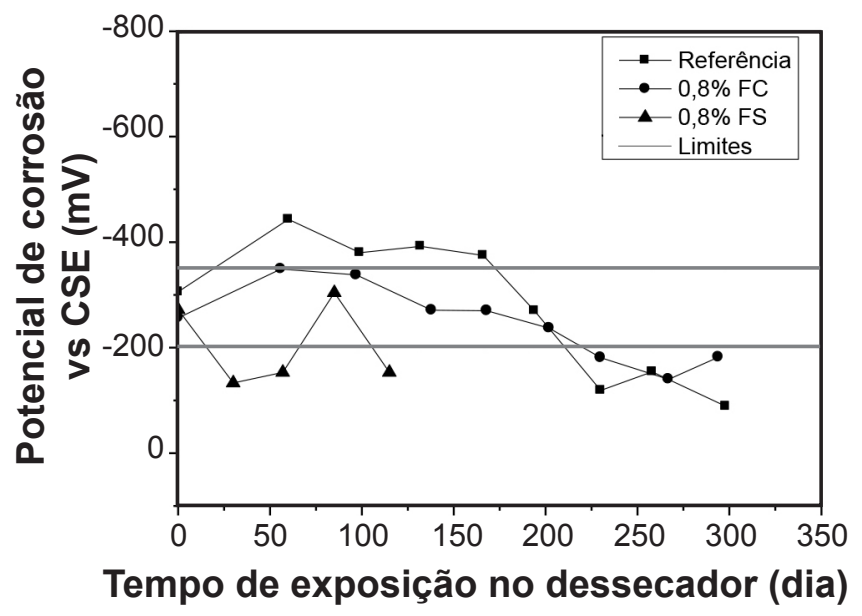

Figura 10: Potencial de corrosão ao longo do tempo para amostras em dessecador.

[Figure 10: Corrosion potential over time for specimens in desiccator.]

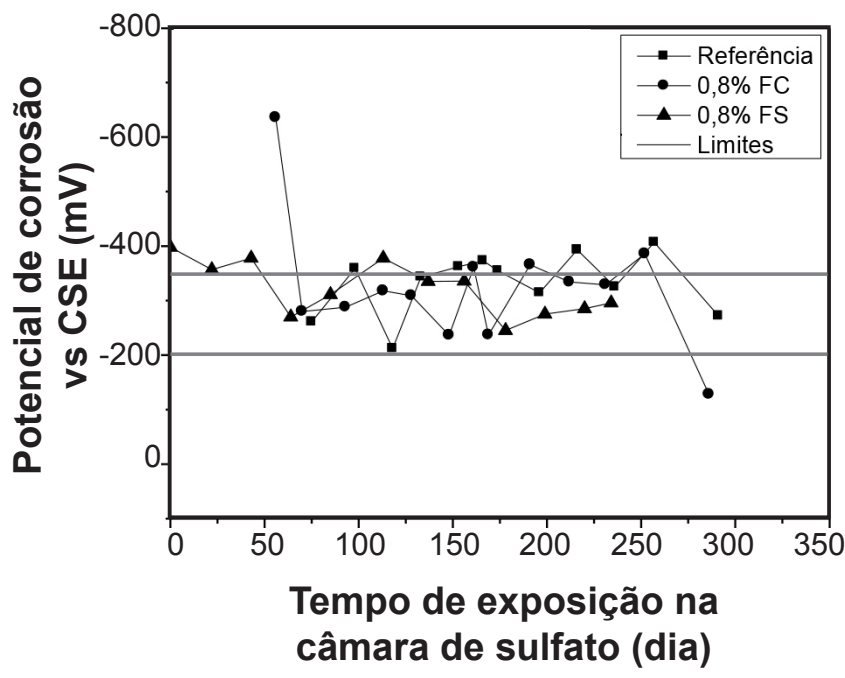

Figura 11: Potencial de corrosão ao longo do tempo para amostras em câmara de sulfato.

[Figure 11: Corrosion potential over time for specimens in sulfur dioxide chamber.]

As amostras com envelhecimento natural tiveram, como resultante, potenciais de corrosão mais positivos que $-200 \mathrm{mV}$. Esta faixa de potencial inferiu a uma probabilidade maior que $90 \%$ de não ocorrer corrosão. Para as amostras submetidas ao ensaio de envelhecimento acelerado em câmara de névoa salina foram obtidos potenciais mais negativos que -350 mV, ou seja, na região de probabilidade de corrosão superior a $90 \%$. Já as amostras de concreto com envelhecimento acelerado em câmara de dióxido de enxofre encontraram-se na região de probabilidade de corrosão incerta por apresentarem potenciais entre -200 e $-350 \mathrm{mV}$. Atribuiu-se o início do processo de corrosão da armadura dentro do concreto para o envelhecimento em câmara de névoa salina e a presença de uma camada de óxido ainda protetora ou passiva na armadura para o envelhecimento em dessecador. A análise taxa de corrosão por outro método analítico, como pela perda de massa ou de espessura, posterior ao ensaio de 


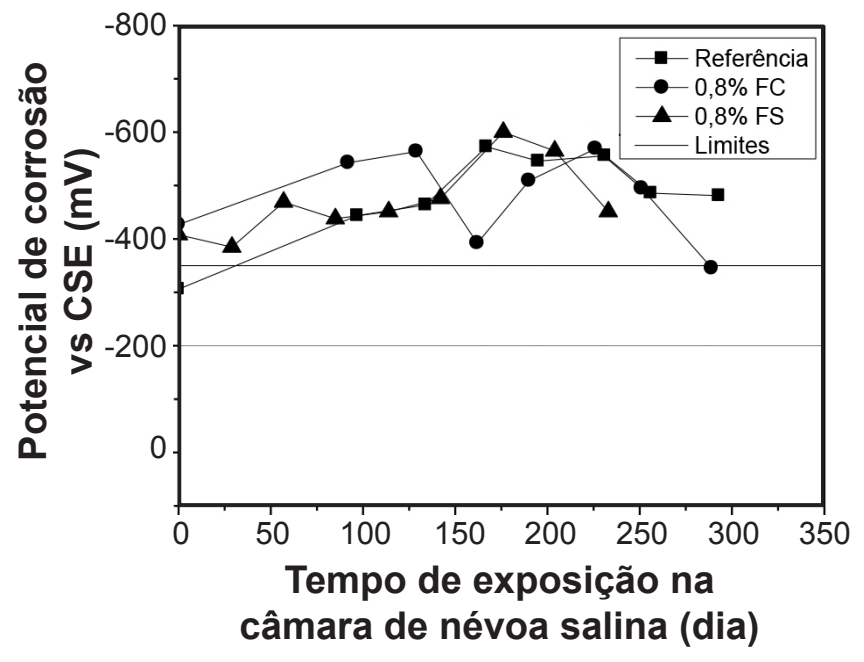

Figura 12: Potencial de corrosão ao longo do tempo para amostras em câmara de névoa salina.

[Figure 12: Corrosion potential over time for specimens in salt spray chamber.]

envelhecimento dos CPs de concreto armado não corroborou com o observado pelo ensaio de potencial de corrosão, em virtude de esta ter sido verificada após um pequeno tempo de exposição e, portanto, ser de baixa sensibilidade analítica [41]. Pode-se constatar pela metodologia adotada que o meio contendo íons cloreto foi mais agressivo em função do tempo do que ao do ataque pelos íons sulfato. Este último, tendeu a favorecer ao preenchimento dos poros do concreto ao longo de uma pequena espessura desde a superfície da estrutura (2 a $3 \mathrm{~mm}$ ) com cristais do tipo filiformes, típicos da etringita $\left(3 \mathrm{CaO} \cdot \mathrm{Al}_{2} \mathrm{O}_{3} \cdot 3 \mathrm{CaSO}_{4} \cdot 32 \mathrm{H}_{2} \mathrm{O}\right)$, já observados na Fig. 7a.

\section{CONCLUSÕES}

Os concretos com adições de $0,8 \%$ FC e $0,6 \%$ FS, de melhor desempenho quanto à compressão axial, apresentaram valores de $16 \%$ e $13 \%$, respectivamente, superiores ao recomendado pelas normas brasileiras para a fabricação de artefatos de concreto tipo postes e cruzetas para as redes de distribuição de energia elétrica. Isto propiciou uma redução de consumo de cimento na mistura de até 5\% em massa, proporcionando também reduções do custo final do produto e dos impactos ambientais atrelados, já que para cada $1 \mathrm{~kg}$ de cimento tem-se, em média, a produção de $0,8 \mathrm{~kg}$ de $\mathrm{CO}_{2}$. A técnica de potencial de corrosão, aplicada para investigar a durabilidade dos concretos com fibras de coco e sisal, indicou a mesma probabilidade de ocorrer corrosão do que o concreto convencional em ambiente marinho e industrial, corroborando para a utilização destes materiais alternativos no concreto, já que apresentaram igual tempo de degradação em ambientes agressivos. A tecnologia desenvolvida para a avaliação ambiental do emprego de argamassas com $\mathrm{TiO}_{2}$, fase anatásio, possibilitou a investigação da fotocatálise do gás $\mathrm{NO}_{\mathrm{x}} \mathrm{e}$, por sua vez, mostrou a eficiência do material desenvolvido na despoluição do ar com estes tipos de poluentes. A argamassa contendo $20 \%$ de $\mathrm{TiO}_{2}$ apresentou eficiência equivalente (aproximadamente $40 \%$ de degradação) às formuladas com teores superiores deste material, e foi a selecionada em virtude da relação custo versus benefício favorável.

\section{AGRADECIMENTOS}

Os autores agradecem o apoio financeiro em infraestrutura, recursos humanos em IT e fomento da COELBA, do LACTEC, da ANEEL, do CNPq/PIBIT e do CNPq lei 8010/90, para a realização desta pesquisa.

\section{REFERÊNCIAS}

[1] S. Wang, X. Han, Adv. Chem. Eng. Sci. 2 (2012) 123128.

[2] F. B. A. Rocha, M. C. Campos, C. R. Colombo, J. E. M. Celestino, XXX Enc. Nac. Eng. Produção, S. Carlos, SP (2010) 1-10.

[3] D. V. Bitencourt, Rev. Fapese 4 (2008) 113.

[4] R. V. Silva, "Compósito de resina de poliuretano derivada de óleo de mamona e fibras vegetais", Tese Dr., Universidade de S. Paulo, S. Carlos, SP (2003).

[5] A. A. Moslemi, Adv. Perform. Mater. 6 (1999) 161-179.

[6] P. Paramasivam, G. K. Nathan, N. C. Das Gupta, Int. J. Cement Composites Lightweight Concrete 6 (1984) 19-27.

[7] J. Khedari, B. Suttisonk, N. Pratinthong, J. Hirunlabh, Cement Concr. Composites 23 (2001) 65-70.

[8] SISAL, Embrapa Algodão. http://www.cnpa.embrapa.br/ produtos/sisal/, acessado em 10/2013.

[9] J. C. Medina, "Plantas fibrosas da flora mundial", Instituto Agronômico de Campinas, Campinas, SP (1959).

[10] L. H. C. Mattoso, F. C. Ferreira, A. S. Curvel, "Sisal Fiber: Morphology and Applications", in: A. L. Leão, F. X. Carvalho, E. Frollini, Lignocellulosic-plastics composites, S.P., USP/UNESP (1997) 241.

[11] S. C. Amico, T. H. S. Costa, L. C. Carrera, W. Santana, D. A. Galvão, Proc. Mater. Sci. 2 (2001) 34.

[12] E. Frollini, J. M. F. Paiva, W. G. Trindade, I. A. T. Razera, S. P. Tita, "Natural Fibers, Plastics and Composites", Kluwer Acad. Publ., EUA (2004) 193.

[13] J. Kuruvilla, R. D. Toledo Filho, J. Beena, T. Sabu, L. H. Carvalho, Rev. Bras. Eng. Amb. 3 (1999) 367.

[14] Cement Technology Roadmap, "Carbon Emissions Reductions up to 2050", World Business Council for Sustainable Development, IEA - International Energy Agency (2009).

[15] L. Osburn, "A Literature Review on the Application of Titanium Dioxide Reactive Surfaces on Urban Infrastructure for Depolluting and Self-Cleaning Applications", CSIR (2008).

[16] A. L. Linsebigler, G. Lu, J. T. Yates, Chem. Rev. 95 (1995) 735.

[17] S. S. Silva, F. Magalhães, M. T. C. Sansiviero, Quim. Nova 33 (2010) 85.

[18] M. D. Gurol, "Photo-catalytic construction materials and reduction in air pollutants", San Diego State Univ., EUA 
(March 2006).

[19] K. Demeestere, J. Dewulf, B. De Witte, A. Beeldens, H. V. Langenhove, "Heterogeneous photocatalytic removal of toluene from air on building materials enriched with $\mathrm{TiO}_{2}$ ", Build. Environ. 43 (2008) 406.

[20] T. Maggos, A. Plassais, J. G. Bartzis, C. Vasilakos, N. Moussiopoulos, "Photocatalytic degradation of NOx in a pilot street canyon configuration using $\mathrm{TiO}_{2}$-mortar panels", Environ. Monit. Assess. 136 (2008) 35.

[21] G. L. Guerrini, E. Peccati, Int. RILEM Symp. Photocatalysis, Itália (2007).

[22] Associação Brasileira de Normas Técnicas, NBR NM 76, "Cimento Portland - Determinação da finura pelo método de permeabilidade ao ar (Método de Blaine)", Rio de Janeiro, RJ (1998).

[23] Associação Brasileira de Normas Técnicas, NBR NM 22, "Cimento Portland com adições de materiais pozolânicos - Análise química - Método de arbitragem”, Rio de Janeiro, RJ (2002).

[24] Associação Brasileira de Normas Técnicas, NBR NM 18, "Cimento Portland - Análise química - Determinação de perda ao fogo", Rio de Janeiro, RJ (2012).

[25] Associação Brasileira de Normas Técnicas, NBR NM 15, "Cimento Portland - Análise química - Determinação de resíduo insolúvel”, Rio de Janeiro, RJ (2012).

[26] Associação Brasileira de Normas Técnicas, NBR NM 13, "Cimento Portland - Análise química - Determinação de óxido de cálcio livre pelo etileno glicol", Rio de Janeiro, RJ (2012).

[27] Associação Brasileira de Normas Técnicas, NBR NM 65, "Cimento Portland - Determinação do tempo de pega", Rio de Janeiro, RJ (2003).

[28] Associação Brasileira de Normas Técnicas, NBR NM 23, "Cimento Portland e outros materiais em pó - Determinação da massa específica", Rio de Janeiro, RJ (2001).

[29] Associação Brasileira de Normas Técnicas, NBR NM 43, "Cimento Portland - Determinação da pasta de consistência normal”, Rio de Janeiro, RJ (2003).

[30] Associação Brasileira de Normas Técnicas, NBR 11578, "Cimento Portland composto - Especificação", Rio de Janeiro, RJ (1991).

[31] Associação Brasileira de Normas Técnicas, NBR 14656, "Cimento Portland e matérias-primas - Análise química por espectrometria de raios X - Método de ensaio", Rio de Janeiro, RJ (2001).

[32] Associação Brasileira de Normas Técnicas, NBR 7211, “Agregados para concreto - Especificação", Rio de Janeiro, RJ (2009).

[33] American Society for Testing and Materials, Annual Book of ASTM Standards, ASTM D 2320, "Standard test method for density (relative density) of solid pitch (picnometer method)", EUA (2012).

[34] Associação Brasileira de Normas Técnicas, NBR 5738, "Concreto - Procedimento para moldagem e cura de corposde-prova", Rio de Janeiro, RJ (2003).

[35] Associação Brasileira de Normas Técnicas, NBR 5739,

"Concreto - Ensaios de compressão de corpos-de-prova cilíndricos", Rio de Janeiro, RJ (2007).

[36] American Society for Testing and Materials, Annual Book of ASTM Standards, ASTM G87-02, "Standard Practice for Conducting Moist $\mathrm{SO}_{2}$ Tests", EUA (2013).

[37] American Society for Testing and Materials, Annual Book of ASTM Standards, ASTM B117-09, "Standard Practice for Operating Salt Spray (Fog) Apparatus", EUA (2009).

[38] American Society for Testing and Materials, Annual Book of ASTM Standards, ASTM C 876, "Standard Test Method for Corrosion Potentials of Uncoated Reinforcing Steel in Concrete", EUA (2009).

[39] Associação Brasileira de Normas Técnicas, NBR 13583 , "Cimento Portland - Determinação da variação dimensional de barras de argamassa de cimento Portland expostas à solução de sulfato de sódio", Rio de Janeiro, RJ (1996).

[40] C. A. Hendriks, E. J. D. Worrel, K. Blok, P. Rime, "Greenhouse Gas Control Technologies", Conf. Paper, Int. Energy Agency, Greenhouse Gas R\&D Programme (2004). [41] K. F. Portella, M. O. G. P. Bragança, M. M. Bonato, J. C. M. dos Santos, D. P. Cerqueira, O. Baron, F. Piazza, A. Joukoski, B. L. Medeiros, P. A. M. Pereira, V. Swinka Filho, E. Esmanhoto, K. J. C. Brambilla, J. M. da Silva, L. Ribeiro, D. H. Ferreira, K. M. Fagundes, M. L. Escobedo, J. L. Bronholo, L. E. Rodrigues, R. G. Soares, L. R. Coelho, M. S. Cabussu, A. C. do Rio, R. C. Kanning, C. M. Gobi, M. E. Vieira, A. C. Carvalho, A. Pescarolo, A. C. Simioni. Rel. Técnico de Pesquisa LACTEC/COELBA/ANEEL, Curitiba, PR (2013).

(Rec.08/01/2014, Rev.08/05/2014, Ac. 28/06/2014) 